\title{
Contribution of pitcher fragrance and fluid viscosity to high prey diversity in a Nepenthes carnivorous plant from Borneo
}

\author{
Bruno Di Giusto ${ }^{1}$, Vladimir Grosbois ${ }^{2}$, Elodie Fargeas ${ }^{3}$, David J Marshall ${ }^{1}$ and Laurence Gaume ${ }^{3, *}$ \\ ${ }^{1}$ Universiti Brunei Darussalam, Biology Department, Jalan Tungku Link, BE 1410 Gadong, Brunei Darussalam \\ ${ }^{2}$ Department of Biometry, CEFE-CNRS, 1919 route de Mende, F-34293 Montpellier cedex 5, France \\ ${ }^{3}$ Botanique et bioinformatique de l'architecture des plantes, UMR CNRS 5120, CIRAD - TA-51 / PS2, \\ Boulevard de la Lironde, F-34398 Montpellier, cedex 5, France \\ *Corresponding author (Email, lgaume@cirad.fr)
}

\begin{abstract}
Mechanisms that improve prey richness in carnivorous plants may involve three crucial phases of trapping: attraction, capture and retention. Nepenthes rafflesiana var. typica is an insectivorous pitcher plant that is widespread in northern Borneo. It exhibits ontogenetic pitcher dimorphism with the upper pitchers trapping more flying prey than the lower pitchers. While this difference in prey composition has been ascribed to differences in attraction, the contribution of capture and retention has been overlooked. This study focused on distinguishing between the prey trapping mechanisms, and assessing their relative contribution to prey diversity. Arthropod richness and diversity of both visitors and prey in the two types of pitchers were analysed to quantify the relative contribution of attraction to prey trapping. Rate of insect visits to the different pitcher parts and the presence or absence of a sweet fragrance was recorded to clarify the origin and mechanism of attraction. The mechanism of retention was studied by insect bioassays and measurements of fluid viscosity. Nepenthes rafflesiana was found to trap a broader prey spectrum than that previously described for any Nepenthes species, with the upper pitchers attracting and trapping a greater quantity and diversity of prey items than the lower pitchers. Capture efficiency was low compared with attraction or retention efficiency. Fragrance of the peristome, or nectar rim, accounted mainly for the observed non-specific, better prey attraction by the upper pitchers, while the retentive properties of the viscous fluid in these upper pitchers arguably explains the species richness of their flying prey. The pitchers of $N$. rafflesiana are therefore more than simple pitfall traps and the digestive fluid plays an important yet unsuspected role in the ecological success of the species.
\end{abstract}

[Di Giusto B, Grosbois V, Fargeas E, Marshall D J and Gaume L 2008 Contribution of pitcher fragrance and fluid viscosity to high prey diversity in a Nepenthes carnivorous plant from Borneo; J. Biosci. 33 121-136]

\section{Introduction}

Nepenthes pitcher plants, like all carnivorous plants, grow in nutrient-poor soils (Juniper et al 1989; Clarke 1997; Ellison et al 2003) and rely mostly on nitrogen derived from the insects that they attract, capture and digest in their pitchershaped leaves (Schultze et al 1997; Moran et al 2001). Most of them are vines characterized by an ontogenetic pitcher dimorphism with young rosette or self-supporting plants exhibiting terrestrial pitchers of the "lower" type and older climbing plants exhibiting aerial pitchers of the "upper" type
(Cheek and Jebb 2001; Di Giusto et al 2008). Until recently, most studies aimed at elucidating the trapping mechanism of Nepenthes pitcher plants focused on the capture and retentive function of slippery surfaces with a special emphasis on the waxy layer that covers the upper inner part of the pitcher in most Nepenthes species (Juniper and Burras 1962; Juniper et al 1989; Gaume et al 2002, 2004; Gorb et al 2005). A study also reported that the trapping surface was the peristome or nectar rim of the pitcher in N. bicalcarata (Bohn and Federle 2004). Nevertheless, some Nepenthes species are polymorphic with regard to the presence of a waxy

Keywords. Attraction; carnivory; digestive liquid; insect capture; Nepenthes rafflesiana; pitcher plant 
layer (Lloyd 1942; Di Giusto et al 2008), while others are monomorphic for the absence of this layer. The presence and size of the peristome is also variable among species (Cheek and Jebb 2001). For example, the pitchers of $N$. inermis and the upper pitchers of $N$. lowii and $N$. campanulata lack both a waxy layer and a peristome (Cheek and Jebb 2001). Moreover, the ontogenetic pitcher dimorphism observed in some species may be accompanied by changes in the plant's trapping strategy. The trapping mechanisms of Nepenthes pitcher plants are, therefore, probably more complex and diverse than previously reported.

The contribution of the digestive liquid to insect retention has never been explored, although some of its physicochemical properties could be involved in trapping. Indeed, Lloyd (1942) and Juniper and co-authors (1989) mentioned the possible presence of a wetting agent in the fluid of Nepenthes and of its American homologue Sarracenia, which could cause insects to sink and be more easily drawn into the pitcher. Furthermore, some species are reported to have a viscous digestive fluid (Cheek and Jebb 2001). Nepenthes inermis, for example, has a highly viscous fluid that could favour the retention of dead prey during heavy rain (Salmon 1993). In Nepenthes rafflesiana var. typica Beck, the upper pitchers do not bear a waxy layer, which characterizes only the lower pitchers of plants during their early development (Di Giusto et al 2008). Moreover, the waxy layer is not very effective in retaining insects in this species and is probably of little adaptive significance considering that no difference in prey capture has been found between waxy traps and non-waxy ones (Di Giusto et al 2008). By contrast, visco-elastic filaments are generated in this species when the pitcher fluid is rubbed between the fingers, suggesting that the fluid could play a role in the capture and retention of insects (personal observation). Nepenthes rafflesiana may thus have evolved mechanisms of retention other than slippery surfaces and could be an appropriate model to obtain a first glimpse of the diversity of trapping mechanisms that may have evolved within the genus.

Prey trapping cannot occur if the plant lacks an efficient attraction system. Until now, quantitative data on insect attraction in pitcher plants have been extremely sparse, although several hypotheses have attempted to explain how pitchers, which resemble flowers in many aspects, attract prey (Joel 1988; Juniper et al 1989). Over short distances, the numerous extra-floral nectaries in these species provide rewarding nectar guides which lead insects to the pitcher mouth, as in Sarracenia carnivorous pitcher plants (Joel 1988; Juniper et al 1989). Over longer distances, spectral reflectance characteristics of the pitcher are implicated in insect attraction in some Nepenthes species (Joel et al 1985; Glossner 1992; Moran 1996; Moran et al 1999), while some American carnivorous plants produce a scent (Joel
1988; Jaffe et al 1995). A sweet scent has been reported to be a chemical cue for attraction in $N$. rafflesiana var. typica in addition to a visual cue linked to the spectral characteristics of the pitcher (Moran 1996). Moran reported that this scent emanates from the pitcher fluid itself. To test the hypothetical attractant power of the fluid, Moran (1996) transposed the "fragrant" fluid of Nepenthes rafflesiana var. typica to emptied pitchers of Nepenthes rafflesiana var. elongata Hort., whose fluid was judged to lack fragrance. Such modified pitchers were compared for prey quantity with control pitchers of Nepenthes rafflesiana var. elongata filled with water. However, this experimental set-up permits only a comparison of the trapping efficiency of the pitcher fluid of Nepenthes rafflesiana var. typica with that of water but does not permit distinction between the attractive and retentive properties of the fluid as a mechanistic explanation. Moreover, this study did not test the possible implication in scent emission of structures of the pitcher itself, such as the peristome or the lid (Phillipps and Lamb 1996). The olfactory cues provided by $N$. rafflesiana thus remain incompletely described. The objective of our study was to clarify the mechanisms involved in trapping in the two pitcher types (upper and lower) of Nepenthes rafflesiana. In particular, we wished to provide clarification on both the attraction and retention mechanisms, and to quantify how these may contribute to the plant trapping system. The number of pitcher visitors (arthropods that visited the pitchers mostly in search of extrafloral nectar) as well as the number of prey items (dead arthropods that were trapped in the pitchers) were analysed for the two pitcher types in populations of this species in Brunei (Borneo). Field experiments were carried out to quantify insect visits and captures by pitchers to elucidate the origin of the scent and to assess the importance of fragrance in insect attraction. Insect bioassays on ants and flies, and measurement of the relative viscosity of the fluid in the two pitcher types were conducted to test whether the physical properties of the fluid were involved in insect retention.

\section{Methods}

\subsection{The carnivorous plant}

The study was carried out at a site located in a degraded kerangas or heath forest in Brunei Darussalam $\left(4^{\circ} 38 \mathrm{~N}\right.$, $114^{\circ} 30$ E) in July 2003 , during the dry season, at the end of a flowering period of $N$. rafflesiana. Typical vegetation included shrubs from the genera Melastomata and Syzygium, and Gleichenia ferns. Nepenthes rafflesiana var. typica is a lowland Nepenthes species, common in such open, wet and often sandy habitats in northern Borneo, northern Sumatra and peninsular Malaysia (Clarke 1997). It is characterized, like most Nepenthes species, by an ontogenetic pitcher 


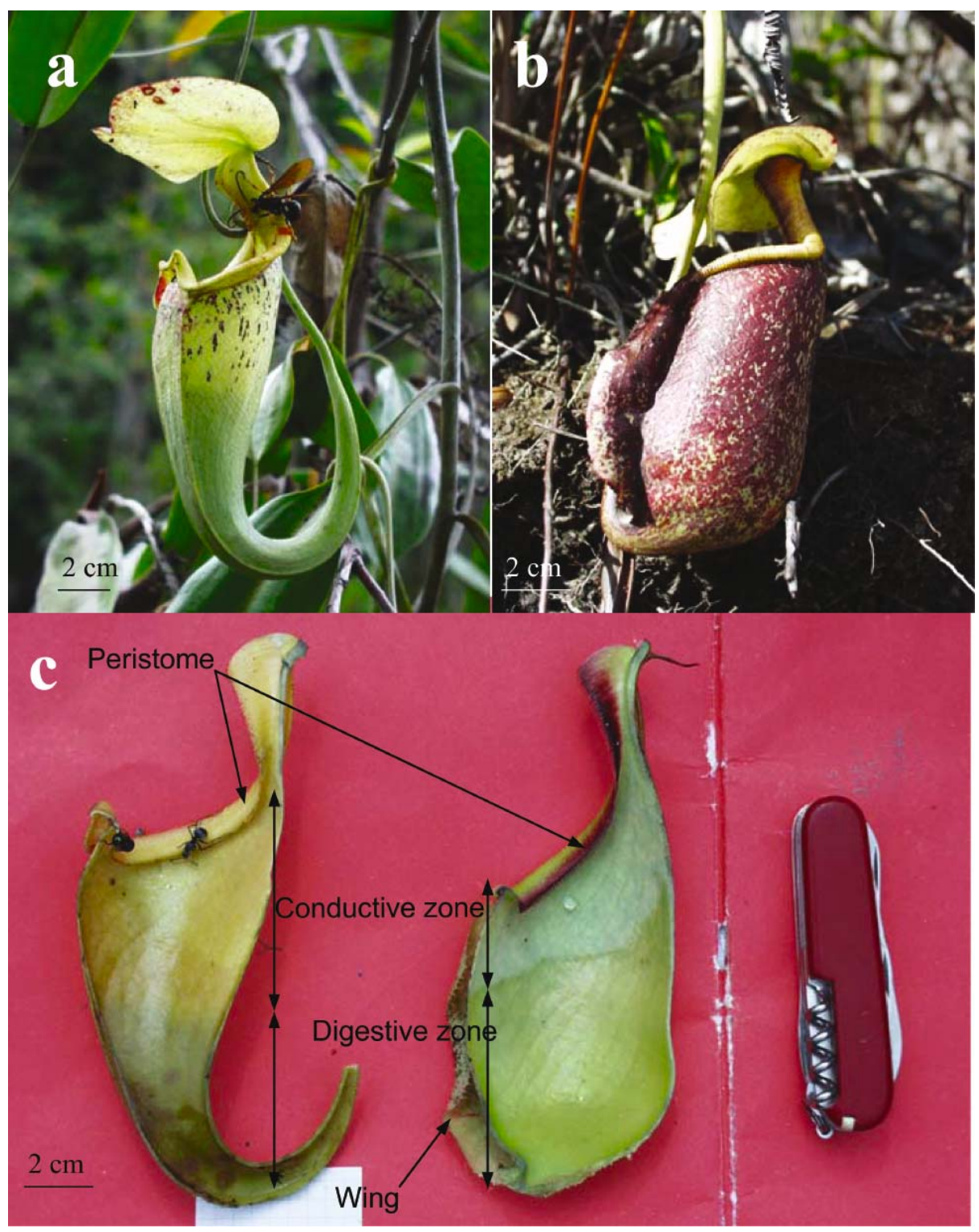

Figure 1. (a) Upper pitcher and (b) lower pitcher of Nepenthes rafflesiana var. typica. (c) Longitudinal sections of both types of pitchers showing the different parts of each pitcher. Note: contrary to the other pitcher parts which are insectless, the peristome of the upper pitcher shows one Polyrhachis ant and one fly that have been attracted.

dimorphism, with the upper pitchers lacking "wings" and being funnel-shaped and more slender at the base than the lower ones found at ground level (figure 1a, b). The lifespan of a pitcher of $N$. rafflesiana is approximately two months for the upper pitchers and two and a half months for the lower ones. The plant is also characterized by numerous extrafloral nectaries that provide extrafloral nectar (EFN) (Adam 1997; Merbach et al 2001). The plant captures a broad range of prey with ants being the most commonly trapped (Adam 1997; Moran 1996; Moran et al 1999). The upper pitchers generally trap more flying prey than the lower ones (Moran 1996; Adam 1997). Three other species of Nepenthes were found at the study site: N. gracilis, $N$. mirabilis var. echinostoma and $N$. ampullaria.

\subsection{Analysis of prey composition}

We collected, in $75 \%$ ethanol, the contents of 17 lower pitchers and 17 upper pitchers from 34 randomly selected $N$. rafflesiana plants. The pitchers were approximately one month old. Using a binocular microscope, we sorted, 
counted and identified the prey to at least genus level for ants, and to family level for other arthropods. Sometimes, the cuticular remains of the arthropods did not permit complete identification (especially in the case of Lepidoptera whose soft wings were always completely digested). These prey items were classified in an "undetermined" group in each order category. Eleven groups were defined: ants, Hymenoptera other than ants, Coleoptera, Diptera, Lepidoptera, Dictyoptera, Orthoptera, Isoptera, Thysanoptera, Araneae and "others", in which were grouped less abundant orders such as Pseudoscorpiones, Neuroptera and Hemiptera. A discriminant analysis was performed on this dataset corresponding to the 34 pitchers to identify the types of prey that differentiate between the two types of pitchers.

\subsection{Attraction experiments}

We gathered empirical data on attraction by observing 17 plants (22 lower and 20 upper pitchers) for 10 minutes, and counting the number of arthropod visitors and their species. We also noted the presence or absence of a sweet scent emanating from the pitchers. Using mixed Poisson regression models, we analysed the effect of the plant (random factor) and the effects of two fixed factors - kind of pitcher (lower vs upper) and presence of odour - on the number of insects or species visiting each pitcher. This experiment was also used to analyse the composition of arthropod visitors classified into flying and non-flying prey. A logistic regression was performed to test for a difference in the fraction of flying visitors between the upper and lower pitchers. A similar analysis was performed to test for a difference in the fraction of flying prey between the two pitcher types.

We then carried out an experiment to elucidate the mechanisms of attraction as well as to determine the parts of the pitcher involved in insect attraction. We selected 11 plants bearing the two kinds of pitchers (lower and upper). The lower pitchers of plants that already bore upper pitchers often came from sprouts of the same plants. For each plant, we selected one lower and one upper pitcher. Each pitcher was held vertically while it was cut at its base to collect fluid. Once empty, the pitchers were then cut longitudinally (figure 1c). We positioned one section of each of the lower and upper pitchers on their dorsal face (with the inner pitcher surface facing upwards), on a sheet of paper at ground level. The two sections were placed $20 \mathrm{~cm}$ away. We put some pitcher fluids from the respective pitcher types in the plastic lids of camera film containers, and positioned each of these cups $10 \mathrm{~cm}$ beneath the relevant section on the sheet of paper. Such cups were thin enough to permit crawling insects to come in contact with the liquid. In each trial, insects were thus permitted to choose between each type of pitcher, and between each part of the pitcher (fluid, external surface, peristome, lower face of the lid, upper face of the lid, conductive zone and digestive zone as defined in figure 1c). This experimental design was duplicated by positioning the second half-pitcher pairs similarly on a second sheet of paper. Two observers (one per sheet) simultaneously recorded, for $10 \mathrm{~min}$, the number of insects and species visiting each pitcher part of the two types of pitcher sections originating from the same plant. For statistical analyses, the insect counts corresponding to the paired trials were pooled for each plant. Mixed Poisson regression models were used to compare the attractiveness of plants (random factor), as well as type of pitcher and part of pitcher (fixed factors). For each pitcher, we carefully smelled both the sectioned pitcher at the level of the peristome and the pitcher fluid placed in the associated cup, and noted the presence (even if not marked) or absence of a sweet scent. Using a mixed logistic regression, we also compared the frequency of presence of a sweet scent between pitchers of the lower and upper forms as well as between the peristome and the fluid.

\subsection{Retention experiments}

In May 2006, at the Universiti Brunei Darussalam, two sets of laboratory experiments to compare the retentive ability of the digestive fluid between the two pitcher types were conducted on ants and flies (Oecophylla smaragdina and Drosophila melanogaster, respectively). In the first experiment, 60 plants were selected (30 with lower pitchers and 30 with upper ones). One pitcher was randomly collected from each plant and transferred to the laboratory with the pitcher contents retained in situ. To test the retentive function of the digestive part only, the conductive zone and the peristome were removed from the pitcher. The Oecophylla ants used for the experiment were captured in the field and the Drosophila flies were reared in the laboratory on a nutritive substrate. One fly was drawn into a soft tube and blown onto the digestive pitcher liquid without finger manipulation. Fly behaviour, including whether the fly escaped or was trapped, was observed for $5 \mathrm{~min}$. A second trial was then conducted on the same pitcher. For each of the 60 pitchers (plants), the frequency of escapes could be either $0 / 2$ or $1 / 2$ or $2 / 2$. Using a logistic regression model, we tested the effect of pitcher type (lower or upper) on the escape frequency of the flies. The experiment and analysis were repeated with the ants on the same set of pitchers.

A second experiment was designed to obtain a relative measurement of the degree of viscosity of the pitcher fluid as compared with that of water. We used microcapillary tubes of $100 \mu 1$ (12.7 cm long) placed vertically in contact with the pitcher fluids inside $2 \mathrm{ml}$ vials. The fluid was collected by making a hole in the basal first third of the pitcher, small enough to prevent the inflow of undigested parts of insects. Using a chronometer, we measured the time needed for 
the liquid to ascend the microcapillary tube and reach a bar level at $3.8 \mathrm{~cm}$ from the base (this arbitrary bar was a standardized mark on the tubes). The fluid for 10 pairs of pitchers (10 lower and 10 upper pitchers less than one month old) belonging to 10 plants was tested. For each pair of pitchers, the ascent time of fluid and water was measured at the foot of the mother plant. The external temperature was also recorded at this point because viscosity varies with the temperature. Each measurement was repeated ten times (total of 300 measurements). An ANCOVA was performed to determine how this ascent time (log-transformed data to fit a normal distribution) varied with the temperature between water and the fluid from the lower and upper pitchers. The rate of fluid ascent depends on its density, its viscosity and its surface properties (Massey 2006). At a given density, the slower the ascent, the more viscous and/or the less wet the fluid. The rate of fluid ascent was found to be lower than that of water. As pitcher fluid and water have comparable densities and wetting abilities (unpublished data), the lower ascent rate of the fluid compared with water was most likely due to its higher viscosity. Our method of measurement (the time for fluid ascent in a standard capillary) is conservative and provides a reliable index of relative viscosity.

\subsection{Statistical analyses}

Data were analysed using the software package SAS v. 8. Three procedures were used for the discriminant analysis.
STEPDISC was used to identify which of the original variables (number of prey belonging to distinct arthropod orders) provided the greatest discrimination between the upper and lower pitchers. CANDISC was used to generate a canonical variable: a linear combination of the original variables providing maximal discrimination between the upper and lower pitchers. DISCRIM was used to assess how well a discriminant criterion based on the value of the canonical variable for the focal pitcher ascribed pitchers to their type (upper or lower). Mixed Poisson and logistic regressions were carried out using the macro GLIMMIX, with a Poisson and a binomial error distribution, respectively. Logistic regressions with fixed effects only were carried out using procedure GENMOD. Correction for overdispersion was applied when necessary using the square root of the ratio of Pearson's $\chi^{2}$ to the associated number of degrees of freedom. For model selection, backward procedures were adopted, starting with removal of the non-significant highest-order interactions.

\section{Results}

\subsection{Analysis of the diversity of prey and arthropod visitors}

The analysis of prey in 17 lower and 17 upper pitchers showed a high diversity of families in this Nepenthes species, consisting of 63 families of arthropods (Appendix 1).

Table 1. Recapitulative statistics on the dataset used in the discriminant analysis

\begin{tabular}{|c|c|c|c|c|c|c|c|c|c|}
\hline \multirow[t]{2}{*}{ Variable } & \multirow[t]{2}{*}{$N$} & \multirow[t]{2}{*}{ Sum } & \multirow[t]{2}{*}{$\begin{array}{l}\text { Mean } \pm \text { SD in } \\
\text { lower pitchers }\end{array}$} & \multirow[t]{2}{*}{$\begin{array}{l}\text { Mean } \pm \text { SD in } \\
\text { upper pitchers }\end{array}$} & \multicolumn{2}{|c|}{$\begin{array}{l}\text { Stepdisc Step } 1 \\
(\mathrm{df} 1,32)\end{array}$} & \multicolumn{2}{|c|}{$\begin{array}{l}\text { Stepdisc Step } 2 \\
(\mathrm{df} 1,31)\end{array}$} & \multirow[t]{2}{*}{$r$} \\
\hline & & & & & $F$ & $P$ & $F$ & $P$ & \\
\hline Coleoptera & 34 & 348 & $0.23 \pm 0.56$ & $20.23 \pm 24.83$ & 11.02 & 0.002 & & & 0.82 \\
\hline Lepidoptera & 34 & 92 & $0.12 \pm 0.33$ & $5.29 \pm 7.26$ & 8.62 & 0.006 & 0.19 & 0.67 & 0.74 \\
\hline Diptera & 34 & 188 & $0.47 \pm 0.80$ & $10.59 \pm 17.87$ & 5.44 & 0.026 & 0.08 & 0.78 & 0.62 \\
\hline $\begin{array}{l}\text { Hymenoptera other } \\
\text { than ants }\end{array}$ & 34 & 130 & $0.12 \pm 0.48$ & $7.53 \pm 13.71$ & 4.96 & 0.033 & 1.83 & 0.18 & 0.59 \\
\hline Dictyoptera & 34 & 29 & $0.12 \pm 0.33$ & $1.59 \pm 2.74$ & 4.83 & 0.035 & 0.03 & 0.86 & 0.58 \\
\hline Thysanoptera & 34 & 6 & 0 & $0.35 \pm 0.70$ & 4.3 & 0.046 & 0.26 & 0.61 & 0.56 \\
\hline Hymenoptera (ants) & 34 & 930 & $22.18 \pm 17.8$ & $32.53 \pm 34.32$ & 1.22 & 0.277 & 0 & 0.98 & 0.31 \\
\hline Isoptera & 34 & 8 & $0.23 \pm 0.56$ & $0.23 \pm 0.44$ & 0 & 1.000 & 0.01 & 0.90 & 0.00 \\
\hline Orthoptera & 34 & 7 & $0.23 \pm 0.97$ & $0.18 \pm 0.53$ & 0.05 & 0.828 & 0.92 & 0.34 & -0.06 \\
\hline Araneae & 34 & 33 & $1 \pm 0.87$ & $0.94 \pm 1.03$ & 0.03 & 0.858 & 1.58 & 0.22 & -0.05 \\
\hline Others & 34 & 5 & $0.12 \pm 0.33$ & $0.18 \pm 0.53$ & 0.15 & 0.700 & 0.26 & 0.61 & 0.11 \\
\hline
\end{tabular}

N, number of pitchers; Sum, sum of arthropods within each order. $F$ and $P$ refer to the classical ANOVA statistics. In the first step of the step-wise discriminant analysis (Stepdisc), the effect of type of pitcher on each candidate variable is tested. The variable whose variation is best explained by type of pitcher (number of prey items belonging to the Coleoptera order) is selected. In the second step, the effect of type of pitcher is tested on the residuals of the regression between each variable and the variable selected at the first step (Coleoptera). $r$ is the coefficient of correlation between each of the variables and the first canonical variable. Flying prey orders are shaded in grey; note that they are the only orders for which the type of pitcher is significantly discriminating. 


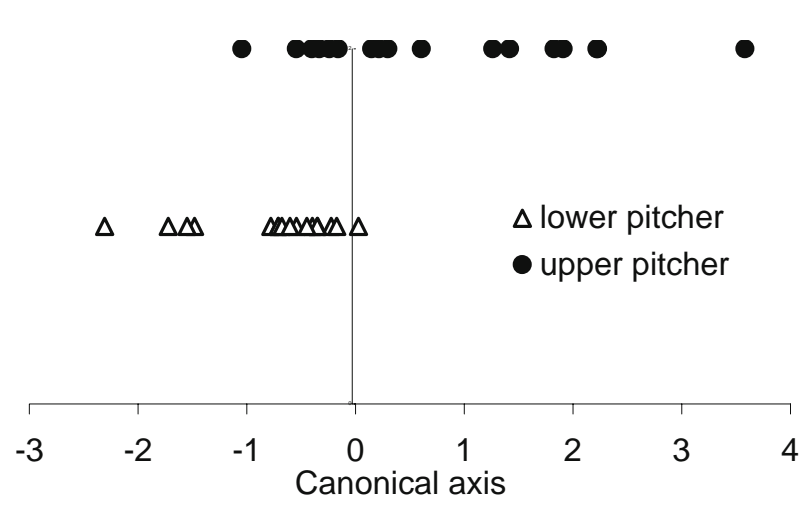

Figure 2. Values of the canonical variable obtained from a discriminant analysis on prey spectra (all arthropod orders) for 34 pitchers. The discriminant analysis produces a criterion for distinguishing between the two types of pitchers (lower vs upper). This criterion is the sign of the canonical variable (negative for lower vs positive for upper). It rightly classified all lower pitchers but one, and 11 out of 17 upper pitchers.

Upper pitchers not only captured more arthropods than lower pitchers (up to three times more) but they also had a larger prey spectrum. Ten orders comprising only 17 families of arthropods, mostly insects, could be identified from the lower pitchers, while 11 orders and up to 59 families were identified from the upper pitchers. All orders belonging to the flying insect category were discriminated between the upper and lower pitchers when tested using single-factor ANOVA models (Step 1, table 1). The variable "Coleoptera" was sufficient to discriminate between the two types of pitchers since no other candidate variable significantly improved the discrimination between the upper and lower pitchers when the effect of "Coleoptera" was accounted for (Step 2, table 1). The canonical variable was positively correlated with the number of prey items belonging to generalist pollinator orders (Coleoptera, Lepidoptera, Diptera, Hymenoptera other than ants, and Thysanoptera; table 1). Insects belonging to these orders were almost exclusively trapped by the upper pitchers, while those of the other orders were trapped indiscriminately by the two pitcher types. But overall, the canonical variable showed no substantial prey segregation by type of pitcher $\left(F_{11,22}=1.24, P=0.32\right)$ partly because, as a consequence of the large number of original variables, this canonical variable was very costly in terms of degrees of freedom. A new analysis was thus performed using only the variables corresponding to the five generalist pollinator orders, which were among the most discriminatory orders. Marginally significant segregation according to pitcher type was detected with this canonical variable $\left(F_{5,28}=2.44, P=\right.$ $0.059)$. The discriminatory criterion based on the canonical variable built with all prey orders classified all the lower pitchers well except one, but wrongly classified 6 out of the 17 upper pitchers (figure 2). The performance of the discriminant criterion, based on the generalist pollinator orders only, was similar. These results arose because the absence of generalist pollinators was a feature shared by all lower pitchers while not all upper pitchers contained generalist pollinators.

In terms of individual richness and at the order level, Hymenoptera, especially the Formicidae species, represented $50.3 \%$ of the prey of upper pitchers, while Coleoptera, especially the Chrysomelidae species, represented $25.4 \%$ of the prey and Diptera, $13.3 \%$. In terms of family richness, Diptera was the most important group. In terms of individual richness, ants constituted the most important prey of the lower (89.3\% of prey) and upper pitchers $(40.8 \%)$. Twenty-three species of ants could be identified, with the more common being Camponotus sp.1, Crematogaster sp. 1, Camponotus gigas, Crematogaster sp. 2, Anoplolepis gracilipes, Crematogaster sp. 3, and Pheidole sp. 1. Camponotus sp. 1 and Crematogaster spp. were common to both types of pitcher while the other three ant species were essentially prey items of the lower pitchers only (Appendix 2).

The visitors recorded during $10 \mathrm{~min}$ observation sessions were essentially nectar-feeding insects such as ants $(66.7 \%$ of individuals), Diptera $(28.6 \%$, half of which were mosquitoes) and Lepidoptera (1.2\% but $4.8 \%$ on the upper pitchers), but also predatory arthropods such as spiders $(3.0 \%)$ or sap-sucking insects $(0.6 \%)$. In the total observation time of $420 \mathrm{~min}, 168$ visitors were observed, and although some were observed in a perilous position, only one (Crematogaster ant) fell inside an upper pitcher.

\subsection{Higher attractive power of upper pitchers and the role of fragrance in insect attraction}

Upper pitchers attracted in natura a greater number of visitors $(5.3 \pm 2.6$ in 10 min observation session) than lower pitchers $(2.9 \pm 2.9)$ and little, if any, variation was detected among plants in insect attraction (table 2a, figure 3a). This higher attractiveness of the upper pitchers could be explained by the sweet odour they produce, since $100 \%$ of the upper pitchers were fragrant $(n=20)$ while only $22.7 \%$ $(n=22)$ of the lower pitchers were fragrant. When present, however, the odour of the lower pitchers was far weaker (as detected by human olfactory perception) than that of the upper pitchers. Fragrance was particularly strong at the level of the peristome. In order to determine if the odour was involved in attraction, we added odour as a factor (presence vs absence) to the model. This factor was highly significant while the type of pitcher was no longer significant when the effect of odour was accounted for. The model that best explained the variation in insect visits was the one taking into account only the random plant effect and the fixed odour effect (with the lowest Akaike information criterion [AIC], 
Table 2. Mixed Poisson regression models testing for the random effect of plant (variance/residual), and the fixed effects of type of pitcher (lower/upper) and/or odour (present/absent) on the number of arthropods that visited the pitcher in natura (a, individuals; $b$, species)

\begin{tabular}{lcccll}
\hline \multicolumn{5}{l}{ a Dependent variable $=$ number of individuals } \\
Covariate & $n d f$ & $d d f$ & $F$ & $P$ & $A I C$ \\
\hline $\begin{array}{l}\text { Plant (0/2.11) } \\
\text { Pitcher }\end{array}$ & 1 & 24 & 6.84 & 0.015 & \\
& & & & & \\
Plant (0/1.88) & & & & NS & 94.4 \\
Pitcher & 1 & 23 & 0.01 & 0.92 & \\
Odour & 1 & 23 & 7.20 & 0.013 & \\
& & & & & \\
Plant (0/1.83) & & & & NS & 93.8 \\
Odour & 1 & 24 & 12.89 & 0.0015 & \\
\hline
\end{tabular}

$\mathrm{b}$ Dependent variable $=$ number of species

\begin{tabular}{llllll} 
Covariate & $n d f$ & $d d f$ & $F$ & $P$ & $A I C$ \\
\hline $\begin{array}{l}\text { Plant (0/0.54) } \\
\text { Pitcher }\end{array}$ & 1 & 24 & 10.84 & 0.003 & \\
& & & & & \\
Plant (0/0.50) & & & & NS & 70.5 \\
Pitcher & 1 & 23 & 0.21 & 0.65 & \\
Odour & 1 & 23 & 5.53 & 0.027 & \\
& & & & & \\
Plant (0/0.49) & & & & NS & 69.8 \\
Odour & 1 & 24 & 15.43 & 0.0006 & \\
\hline
\end{tabular}

The Akaike information criterion (AIC) is given for each model (the smallest value indicates the best model). NS, nonsignificant.

table 2a). Therefore, most of the differences observed in insect visits between the two types of pitchers were due to a difference in their scent.

Upper pitchers also attracted a greater number of species $(2.5 \pm 1)$ than lower pitchers $(1.4 \pm 0.9)$ and their odour accounted for most of the differences observed (same statistical approach, table $2 \mathrm{~b}$, figure $3 \mathrm{a}$ ).

\subsection{Attraction of different parts of the pitchers: the olfactory cue of the peristome}

When pitchers were longitudinally cut and placed at ground level, the upper pitchers still attracted more arthropods than the lower ones (mixed Poisson regression model, effect of the fixed factor: type of pitcher, $F_{1,134}=28.75, P$
$<0.0001$, figure $3 b)$. This greater number of insect visits to the upper pitchers could be mostly attributed to the greater attractiveness of their peristome (effect of the fixed factor: plant part $F_{6,134}=10.25, P<0.0001$, figure $3 \mathrm{~b}$, illustrated in figure $1 \mathrm{c})$. The attractiveness of the different parts was not significantly different among pitcher types (interaction pitcher* part: $F_{6,128}=1.69, P=0.13$ ). Plants in this analysis differed slightly in their attractiveness (effect of the random plant factor: variance $=0.14$, residual $=0.88)$.

The presence or absence of odour appeared to be obviously correlated with the extent of insect attraction. Indeed, a greater proportion of upper pitchers produced a sweet scent and the peristome appeared to be more often odoriferous than the pitcher fluid of both the lower and the upper pitchers, while individual plants differed significantly in their odour (mixed logistic regression on the presenceabsence of odour from the data subset corresponding to the peristome and liquid parts, table 3 ).

\subsection{Untargeted attraction but targeted retention of upper pitchers towards flying insects}

Interestingly, the fraction of flying insects in the visitor spectrum was comparable for lower and upper pitchers (logistic regression, likelihood ratio test corrected for overdispersion: $F_{1,35}=0.07, P=0.80$, figure 4), being significantly less than 0.5 for both the lower (Wald test: $\chi^{2}=$ 4.8, $P=0.03$ ) and the upper pitchers (Wald test: $\chi^{2}=6.1, P$ $=0.01)$. By contrast, the fraction of flying insects in the prey spectrum was far higher for the upper than the lower pitchers (logistic regression: $F_{1,32}=45.11, P<0.0001$, figure 4), being significantly less than 0.5 in the lower pitchers (Wald test: $\chi^{2}=4.8, P=0.03$ ), while marginally significantly greater than 0.5 in the upper pitchers (Wald test: $\chi^{2}=3.4, P=0.06$ ). These comparisons suggest that the upper pitchers are either more efficient than the lower pitchers in retaining flying insects or less efficient than the lower pitchers in retaining non-flying arthropods (ants for the major part). The latter hypothesis was not supported since the cumulative number of non-flying arthropods in the two pitcher types was quasiproportional in the visitor and prey spectra (visitors: 45 in the lower pitchers, 72 in the upper pitchers; prey items: 396 in the lower pitchers, 572 in the upper pitchers; $\chi^{2}=$ $0.26, P=0.61$, while this was not at all the case for flying insects (visitors: 18 in the lower pitchers, 33 in the upper pitchers; prey items: 18 in the lower pitchers, 782 in the upper pitchers; $\left.\chi^{2}=129.2, P<0.0001\right)$. For non-flying arthropods, the difference in capture between the lower and upper pitchers should be ascribed to differences in their attraction pattern, while for flying insects, it should be more particularly ascribed to the higher retentive capacity of the upper pitchers. 

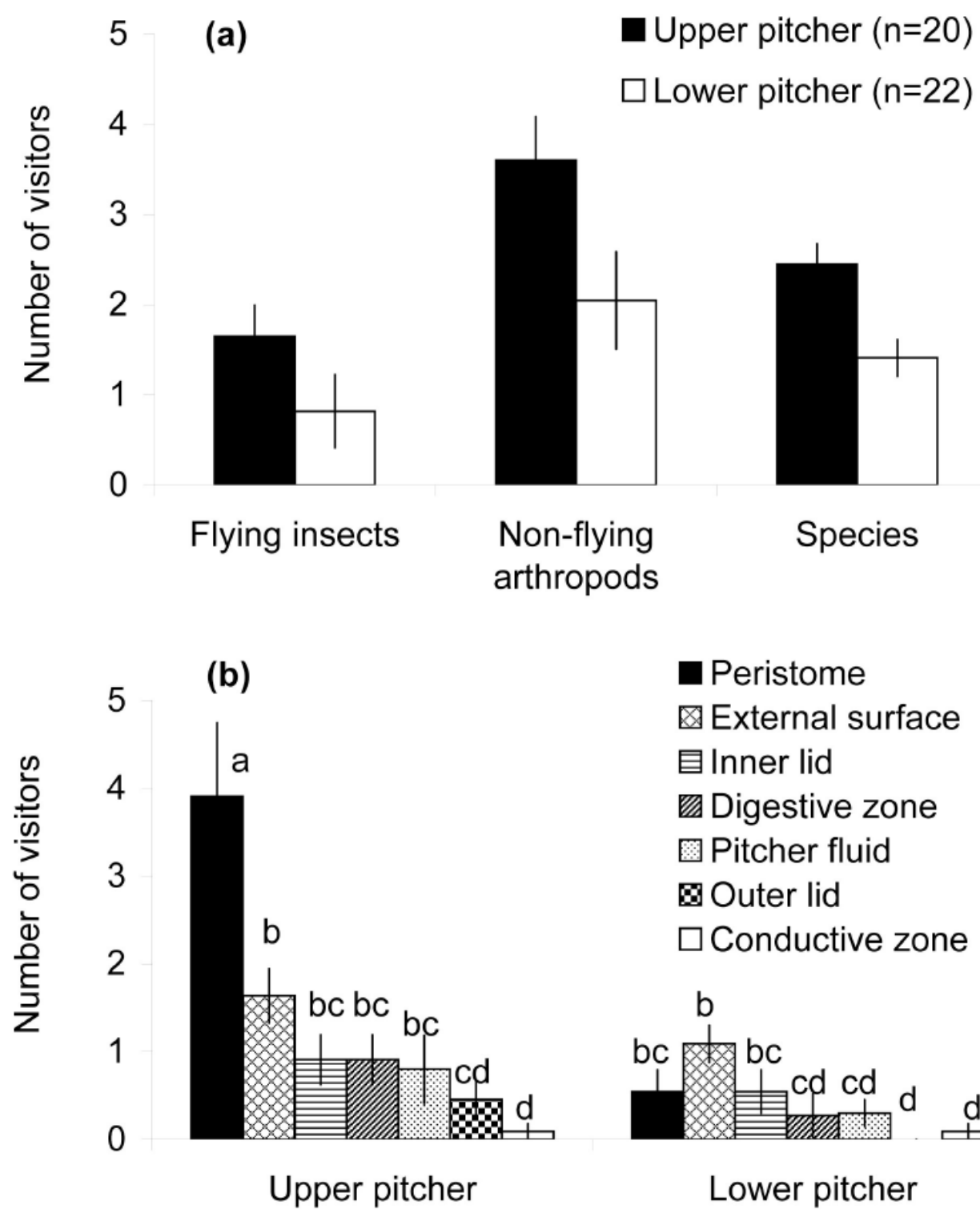

Peristome

External surface

目Inner lid

Digestive zone

圈 Pitcher fluid

Outer lid

$\square$ Conductive zone

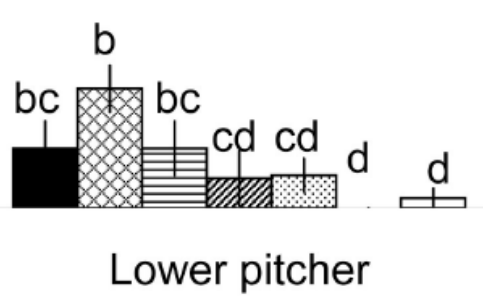

Figure 3. Attraction compared for lower and upper pitchers during 10 min observation sessions. (a) Mean ( \pm SE) number of flying, non-flying arthropods and species that visited pitchers of $N$. rafflesiana in natura. (b) Mean $( \pm \mathrm{SE})$ number of visitors on the different parts of pitchers longitudinally cut and placed at ground level. Different letters indicate significantly different means, as determined by $t$-tests.

\subsection{Insect retention and analysis of fluid viscosity}

Retention of the experimental insects within the digestive part of the pitcher was universally high for both ants and flies, and for the two pitcher types. While all the 120 Oecophylla smaragdina ants were retained inside the pitcher fluid, 22 out of the 120 Drosophila melanogaster flies escaped, all from the fluid of the lower pitchers (figure 5). Therefore, there was a significant effect of pitcher type (lower/upper) on the retention rate of flies (Logistic regression: $\chi^{2}=35.48$, $P<0.0001)$. All the insects that did not escape from the liquid during the $5 \mathrm{~min}$ observation period died within $20 \mathrm{~min}$. These insects became embedded in the fluid and most of them were unable to remove their legs from the fluid. The ants were rapidly drawn into the liquid where they sank. The flies were not capable of flight but could still slowly move their wings, though with greater difficulty in the upper than the lower pitchers. They thereby maintained themselves at the surface of the digestive liquid for longer periods. Those that succeeded in escaping from the fluid in the lower pitchers swam to the digestive wall and slowly hauled themselves out of the fluid. They cleaned themselves 
Table 3. Mixed logistic regression model testing for the random effect of plant (variance/residual), and the fixed effects of type of pitcher (lower/upper) and pitcher part (peristome/fluid) on the presence/absence of a sweet scent. S, significant

\begin{tabular}{|c|c|c|c|c|c|c|}
\hline Covariate & $n d f$ & $d d f$ & $F$ & $P$ & Estimate & $\mathrm{SE}$ \\
\hline Plant $(4.27 / 0.55)$ & & & & $\mathrm{S}$ & & \\
\hline Pitcher & 1 & 28 & 14.54 & 0.0007 & & \\
\hline Part & 1 & 28 & 10.11 & 0.0036 & & \\
\hline \multicolumn{7}{|l|}{ Parameter } \\
\hline Intercept for upper pitcher and part $=$ fluid & & & & & 1.65 & 0.91 \\
\hline Intercept increment for lower pitcher & & & & & -3.28 & 0.86 \\
\hline Intercept increment for part $=$ peristome & & & & & 2.55 & 0.80 \\
\hline
\end{tabular}

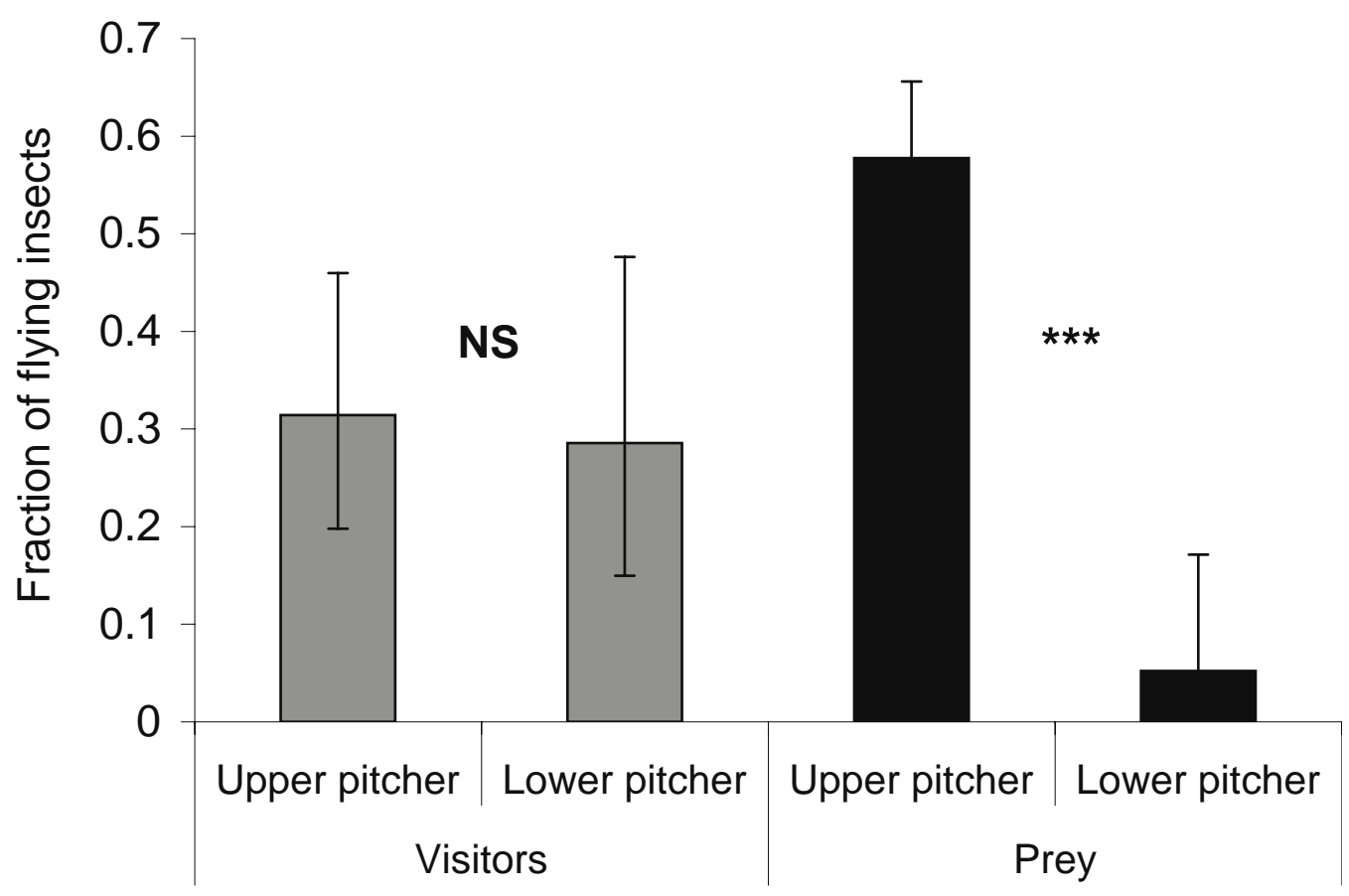

Figure 4. Fractions of flying insects in the visitor and prey spectra compared for lower and upper pitchers. Mean ( \pm confidence intervals). NS, non-significant difference; ***, significant difference; $P<0.001$ according to likelihood ratio tests corrected for overdispersion.

and let their wings dry for several minutes before taking off.

In the experiment aimed at assessing the relative viscosity of the pitcher fluid, the ANCOVA performed on the log-transformed time measures of the fluid ascent explained $72 \%$ of the variance. The residuals were normally distributed (Shapiro statistic, $W=0.98, P=0.12$ ). Type of fluid greatly affected the duration of fluid ascent, the ascent being slowest for the upper pitcher fluid, medium for the lower pitcher fluid, and quickest for water (effect of type of fluid: $F_{2,290}=8.70, P=0.0002$, figure 6). Temperature affected ascent time differently according to the type of fluid (interaction effect: temperature*type of fluid: $F_{2,290}=21.43$, $P=0.0001$, effect of temperature: $F_{1,290}=2.14, P=0.14$ ). While duration of fluid ascent decreased with temperature for water, it increased with temperature with approximately the same slope for the two pitcher fluids (figure 6).

\section{Discussion}

Carnivory requires well-developed mechanisms of insect attraction, capture, retention and digestion (Lloyd 1942; Juniper et al 1989). The carnivorous pitcher plant, Nepenthes 


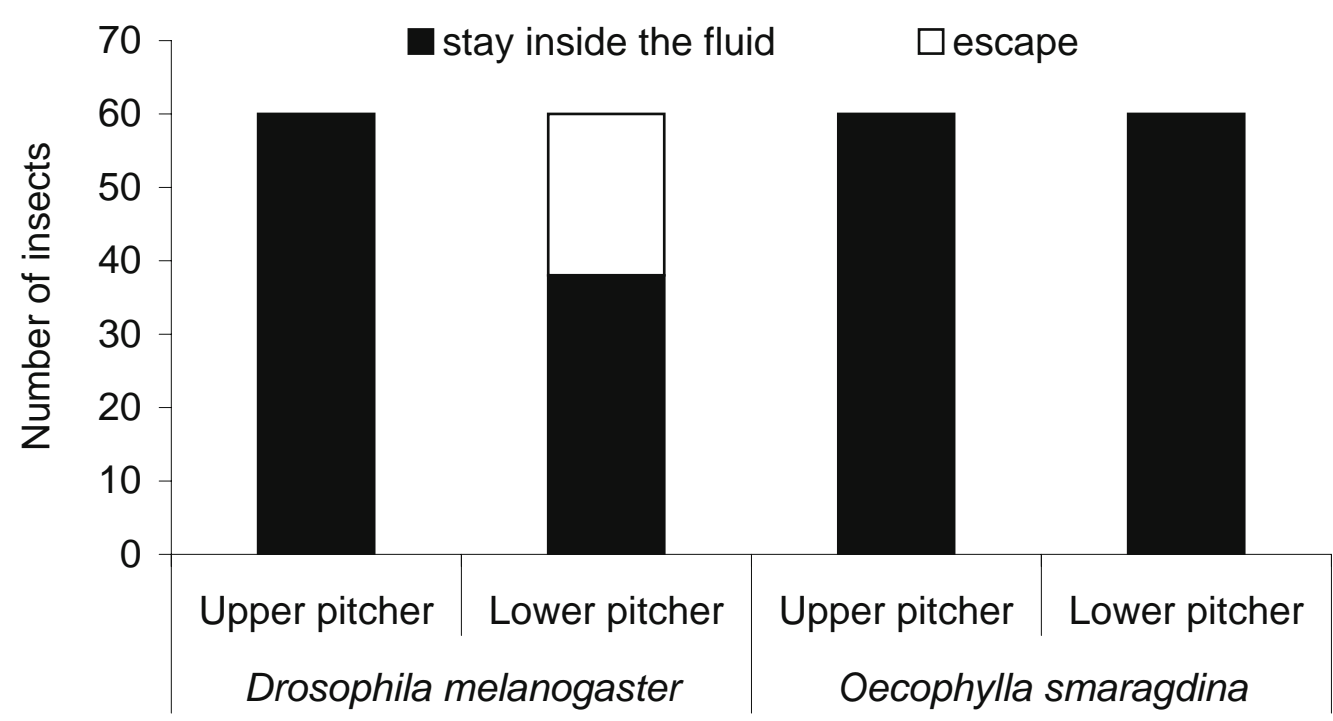

Figure 5. Retention experiment to show the proportions of insects that were retained within or succeeded in escaping from the pitcher fluid, compared for the two types of pitchers and for ants and flies.

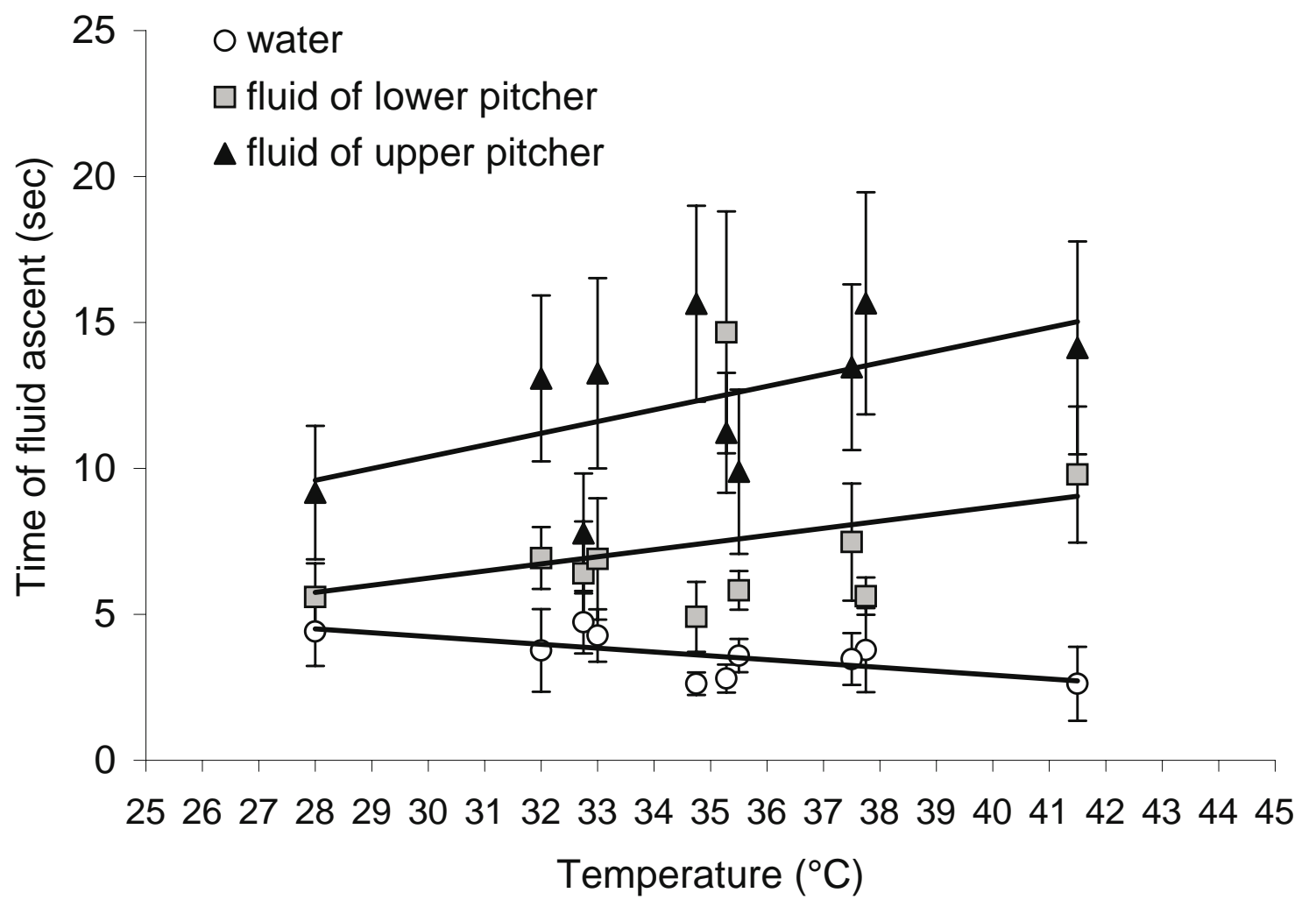

Figure 6. Mean $( \pm$ SD) index of viscosity compared for water, and lower and upper pitcher fluid, at different temperatures. The relative viscosity was assessed by measuring the time for fluid ascent up to an arbitrary height of $3.8 \mathrm{~cm}$ in $100 \mu 1 \mathrm{microcapillary}$ tubes. 
rafflesiana var. typica, is shown to have a low temporal rate of insect capture despite having high powers of attraction and retention. The plant is also characterized by a high prey diversity, which is especially true for the upper pitchers. The higher quantity and diversity of prey in the upper pitchers can be explained by the emission of an attractive fragrance from their peristome and by the better retentive properties of their pitcher fluid.

\subsection{Low rate of insect capture compared to insect visits}

According to our systematic daytime observations, the plant seems to nourish more insects than it feeds on (only 1 capture in 168 insect visits to EFN). Our quantitative results confirm the observations made for other Nepenthes species (Joel 1988; Moran 1996; Merbach et al 2001) and for other pitcher plants (e.g. Newell and Nastase 1998). The relationship between the carnivorous plant and its guild of EFN consumers is complex. In tropical rainforests, plant exudates constitute the main diet of arboricolous ants (Davidson et al 2003, Blüthgen and Fiedler 2004) and can mediate loose ant-plant mutualisms (e.g. Di Giusto et al 2001; Gaume et al 2005) or tighter ones where ants actively protect their host plant against herbivores (e.g. McKey et al 2005). The relationships between the EFN-visiting ants and the carnivorous plant are thus not necessarily antagonistic. The ants could also be involved in a nutritional mutualism (Joel 1988). The plant provides lower cost carbohydrate-rich EFN to the ants and is supplied from time to time with the highly beneficial nitrogen (limiting in habitats of carnivorous plants) derived from trapped ants. Besides ants, the plant also feeds on another potentially useful group of EFN visitors, i.e. mosquitoes, which lay their eggs inside the pitchers and whose emerging larvae accelerate prey breakdown and nitrogen release (Beaver 1983). Many larvae of different species of mosquitoes and midges were found in the pitcher fluids but this inquiline community was not relevant to the study.

Another explanation for the observed low rate of insect capture compared with insect visits is that we could have missed periods of more efficient prey capture. For example, several insects, such as Camponotus gigas ants, Dictyoptera, Isoptera, some Orthoptera or moths, observed in our prey sample are known to be nocturnally active on plants and might be captured more frequently at night. Moreover, the discovery of the wettability properties of the peristome in $N$. bicalcarata suggests that pitchers could be more efficient as "aquaplaning" traps during rain or periods of high nectar production (Bohn and Federle 2004). Some flowervisiting insects might also be trapped en masse during plant flowering. This would explain the presence of numerous Chrysomelidae in our prey samples and their absence as pitcher visitors.

\subsection{High prey diversity and the functional roles of pitcher types in prey segregation}

The analysis of prey richness shows that $N$. rafflesiana var. typica traps a large prey spectrum including at least 63 families of arthropods and at least 23 species of Formicidae. The prey diversity was found to be higher than previously described (34 families in the dataset of Moran shown by Clarke 2001) and this was particularly true for insects belonging to the flying category. Confirming the results of Moran (1996), the upper pitchers were found to trap more flying insects than the lower pitchers, although this difference was more pronounced in the present study. In contrast to Moran (1996) but similar to Adam (1997), we show that the upper pitchers trap more arthropods than the lower pitchers in total (including flying and non-flying insects). An initial hypothesis could be that seasonal or site effects accounted for the observed differences. Alternatively, Moran (1996) might have underestimated the number of arthropods trapped in his experimental set-up, especially those belonging to the flying category or those trapped in the upper pitchers. Indeed, he analysed the prey contents of pitchers previously emptied and filled with water, assuming thereby that the retentive capacities of the pitcher fluids were similar to that of water. But the digestive fluid is more viscous than water and such a physical property should make it behave very differently from water with regard to insect trapping. Moreover, the fluid of the upper pitchers is more viscous than the fluid of the lower ones and, according to our preliminary experimental data, more efficient in trapping flies.

The prey segregation according to pitcher type partly explains the large diet diversity of Nepenthes rafflesiana var. typica. As stressed by the comparison of prey and visitor spectra between the two pitcher types, the specialization of the upper pitchers in trapping flying insects appears to be more the consequence of a targeted retention than a targeted attraction (as suggested by Moran [1996]). The ontogenetic pitcher dimorphism is accompanied by a dual strategy in this climbing plant, which permits the successive capture of prey belonging to both terrestrial and arboreal strata. Lower pitchers are specialized in capturing ants, the most important group of terrestrial arthropods, whose species abundance in the leaf litter in northern Borneo is comparable to that found in upper vegetation layers (Brühl et al 1998). The upper pitchers are different from the lower ones in being able to trap insects belonging to the flying category, which are more diverse and abundant in the upper vegetative layers (Stork 2003). This dual strategy permits this carnivorous plant to enlarge its ecological niche and should contribute to its great ecological success, as assessed by a rather dense distribution in the habitats where it occurs (Clarke 2001) and a high ability for colonization (personal 
observation). As a matter of fact, Nepenthes rafflesiana, which obtains most of its nitrogen from insects (Moran et al 2001), is one of the species from northern Borneo whose leaves are the richest in N, P and K (Osunkoya et al 2007).

\subsection{High attractive power of upper pitchers and the role of sweet scent in insect attractio $\mid n$}

The overall greater attractive power of the upper pitchers is not the sole result of a greater abundance of arthropods in the upper vegetation layers since, even at ground level, upper pitchers were found to attract more arthropods than lower ones. This success mostly arises from their stronger fragrance. We are aware that the human sense of smell cannot necessarily reflect the olfactory perception of insects and that each category of insect having its own olfactory ability should recognize more or less specific cues. Nevertheless, pollinating insects, at least, are known to be mostly attracted by floral or sweet fragrances and the presence/absence of such a type of fragrance in Nepenthes rafflesiana revealed itself to be the factor most affecting insect visits to pitchers. Such a strong correlation supports the hypothesis of Moran (1996) and confirms that olfactory cues play a significant role in the attraction system of $N$. rafflesiana, as seems to be the case for other carnivorous pitcher plants including the American Sarraceniaceae (Miles et al 1975; Joel 1988; Jaffe et al 1995). The upper pitchers were also shown to attract a greater diversity of arthropods than the lower ones and, among them, several potential generalist pollinators. We expect that the carnivorous plant, which is able to mimic flowers in a number of morphological ways (Joel 1988), is also capable of mimicking flowers chemically. Moran (1996) and Moran et al (1999) have also demonstrated the role of spectral reflectance characteristics of the pitcher in insect attraction. In Nepenthes rafflesiana, the peristome is UV-absorptive while the outer pitcher body is UV-reflective, producing a contrasting pattern which could be interpreted as a visual stimulus for insects such as hymenopterans and dipterans. In our experimental design, only the inner faces of pitcher bodies were exposed to insects. According to the photographs of Moran (1996), the inner face of the upper pitchers is not UV-reflective, and for the lower pitchers, even if the possible presence of wax makes it reflective, its contrasting pattern with the peristome would not explain why paradoxically insect visits were far less frequent for the lower pitchers than for the upper ones. Hence, the most plausible explanation in our case was that the sweet scent emitted by the upper pitchers in particular was mainly responsible for insect attraction. Finally, our statistical analysis not only confirms the hypothesis of Moran that olfactory cues accounted for the attraction of the flying insects, but further shows that sweet scent plays an important role in the general attraction system of the pitcher plant and substantially targets not only flying insects but also ants. Moran suggested that the liquid was the odour source. We show that the peristome of the upper pitchers is not only the most attractive but also the most fragrant part of the plant. This raises the question as to whether the extrafloral nectar, which is secreted by nectaries situated between the teeth on the rim, is involved in the emission of volatile compounds. The peristome is easily wetted by such nectar secretions which spread out all along its surface. This would not only facilitate insect aquaplaning (Bohn and Federle 2004) but would also enable a more efficient emission of attractive volatile compounds.

\subsection{Viscosity of pitcher fluid as a mechanism of insect retention}

Our measures of relative viscosity based on fluid ascent in a capillary showed that the digestive fluid of the pitcher plant is more viscous than water. We found that the ascent time of water decreased with increasing temperature. The viscosity of water, the fluid of reference, is indeed expected to decrease with temperature (Massey 2006). However, why does the viscosity of the pitcher fluid increase with temperature? The composition of the fluid as well as its structure might change with temperature. For example, the digestive liquid contains several enzymes whose activity is dependent upon $\mathrm{pH}$ and temperature (Lüttge 1983), and should change its properties. Some proteins may also flocculate at elevated temperatures. More probably, evaporation of water in the fluid, especially of the surplus water coming from rainfall (Clarke 2001), could occur when temperature increases. This evaporation would concentrate the macromolecules responsible for fluid viscosity.

Interestingly, fluid viscosity seems to be higher in the upper pitchers than in the lower ones. This difference could partly explain the higher abundance and diversity of prey found in the upper than in the lower pitchers. Indeed, even though details of the mechanism remain unclear, the viscosity of the pitcher fluid seems to play a role in insect retention by impeding the locomotion of ants and limiting wing movement in flies. Moreover, flying insects were the particular prey target of the upper pitchers and the experimental Drosophila were better retained in the fluid of the upper pitchers than in the fluid of lower ones. We thus hypothesize that the fluid of higher viscosity in the upper pitchers is responsible for their better retention of flying insects. Moreover, the fluid of the waxless Nepenthes inermis, $N$. eymae, $N$. aristolochioides, $N$. dubia and $N$. jacquelinae has been reported to be particularly viscous and such viscous properties could serve to retain dead prey in the event of flooding during rain (Salmon 1993; Cheek and Jebb 2001) or even occasionally to act as flypaper traps (Clarke 2001). Supporting our hypothesis, $N$. inermis was reported 
to be (under the name of $N$. bongso) specialized in trapping midges (Kato et al 1993). A similar pattern was observed for $N$. aristolochioides while $N$. jacquelinae was observed to trap essentially flying prey of larger dimensions (Clarke 2001). The prey composition of the two other species, $N$. dubia and N. eymae, is unknown. Fluid viscosity certainly does not play an exclusive role in the retention system of $N$. rafflesiana. The tendency of trapped insects to sink into the pitcher fluid in the lower as well as upper pitchers could suggest increased wetting properties of the fluid, which could also play a role in the retentive function of the pitcher. We propose that the retentive properties of the fluid are of fundamental importance in Nepenthes species that lack key trapping attributes such as a slippery waxy layer (Juniper and Burras 1962; Gaume et al 2004) or a slippery wettable peristome (Bohn and Federle 2004).

In conclusion, this study has clarified the respective contributions of attraction and retention in the trapping efficiency of different categories of arthropods in $N$. rafflesiana var. typica. Upper pitchers were shown to trap higher numbers of arthropods than lower ones, partly because they exhibited a higher overall attraction and especially because they had a more efficient system of special retention of flying prey. The main mechanism of attraction was shown to be the emission of a sweet fragrance mostly from the peristome. The so far unexplored mechanism of retention has to be linked to the viscosity of the fluid but further research is needed to clarify the physical processes involved. The pitcher dimorphism induced by plant development is thus accompanied by a dual strategy, which permits the climbing plant to extend its ecological niche and adapt to the resource input: the insect guild structure of the explored stratum. The pitchers of these carnivorous plants are therefore more than simple pitfall traps and the different Nepenthes species seem to have developed a broad spectrum of trapping devices which would be worthwhile to studying these through comparative analysis of the chemical and physical pathways in an "evo-devo" context.

\section{Acknowledgements}

We thank K Abu Salim, D Lane, and D Edwards for their administrative help in the Universiti Brunei Darussalam. We are grateful to the Forestry Department who provided us permits to carry out this research in the field. We also acknowledge S Nyawa from the Brunei Museum and CITES commission and Mr Idris from the National Herbarium of Brunei. This research was partly funded by a "Young researcher and innovative project" grant awarded to LG from the University Montpellier II. Y Forterre is thanked for his invaluable advice in physics, M Guéroult for his efficient help in the field, as well as E Jousselin and V Bonhomme for their helpful comments on the manuscript.
Appendix 1. Prey composition compared for lower and upper pitchers. The cumulative numbers of arthropods (percentage in brackets) is given for each order or family. Within the Diptera, B, C, N refer to Brachycera, Cyclorapha and Nematocera suborders. NI, not identified.

\begin{tabular}{|c|c|c|c|}
\hline $\begin{array}{l}\text { Numbers of arthropods in } \\
\text { the different taxa (\%) }\end{array}$ & $\begin{array}{l}\text { Lower } \\
\text { pitchers } \\
(n=17)\end{array}$ & $\begin{array}{l}\text { Upper } \\
\text { pitchers } \\
(n=17)\end{array}$ & Total \\
\hline HYMENOPTERA & $379(89.9)$ & $681(50.3)$ & $1060(59.7)$ \\
\hline Formicidae & $377(89.3)$ & $553(40.8)$ & $930(52)$. \\
\hline Vespidae & 0 & 2 & 2 \\
\hline Apidae & 0 & 22 & 22 \\
\hline Megachilidae & 0 & 2 & 2 \\
\hline Sphecidae & 0 & 1 & 1 \\
\hline Chalcidoidea & 2 & 62 & 64 \\
\hline Others NI & 0 & 39 & 39 \\
\hline COLEOPTERA & $4(0.9)$ & $344(25.4)$ & $348(19.6)$ \\
\hline Chrysomelidae & 3 & 258 & 261 \\
\hline Curculionidae & 0 & 18 & 18 \\
\hline Scarabeidae & 0 & 1 & 1 \\
\hline Melolonthidae & 0 & 9 & 9 \\
\hline Cetoniidae & 0 & 2 & 2 \\
\hline Tenebrionidae & 0 & 1 & 1 \\
\hline Anthicidae & 0 & 2 & 2 \\
\hline Buprestidae & 0 & 1 & 1 \\
\hline Elateridae & 0 & 13 & 13 \\
\hline Cantharidae & 0 & 1 & 1 \\
\hline Silphidae & 0 & 1 & 1 \\
\hline Scirtidae & 0 & 7 & 7 \\
\hline Clambidae & 0 & 1 & 1 \\
\hline Histeridae & 0 & 8 & 8 \\
\hline Others NI & 1 & 21 & 22 \\
\hline DIPTERA & $8(1.9)$ & $180(13.3)$ & $188(10.6)$ \\
\hline Muscidae (C) & 0 & 1 & 1 \\
\hline Calliphoridae (C) & 0 & 3 & 3 \\
\hline Drosophilidae (C) & 0 & 5 & 5 \\
\hline Dryomyzidae (C) & 0 & 1 & 1 \\
\hline Chamaemeyiidae (C) & 0 & 2 & 2 \\
\hline Otitidae (C) & 0 & 1 & 1 \\
\hline Syrphidae (C) & 1 & 9 & 10 \\
\hline Ephydridae (C) & 0 & 5 & 5 \\
\hline Conopidae (C) & 0 & 2 & 2 \\
\hline Michiliidae (C) & 0 & 4 & 4 \\
\hline Chloropidae (C) & 0 & 2 & 2 \\
\hline Psilidae (B) & 0 & 1 & 1 \\
\hline Stratiomyiidae (B) & 0 & 3 & 3 \\
\hline Dolichopodidae (B) & 0 & 1 & 1 \\
\hline Tabanidae (B) & 0 & 1 & 1 \\
\hline Bibionidae $(\mathrm{N})$ & 0 & 18 & 18 \\
\hline
\end{tabular}




\begin{tabular}{|c|c|c|c|}
\hline Cecidomyiidae (N) & 0 & 7 & 7 \\
\hline Ceratopogonidae $(\mathrm{N})$ & 0 & 5 & 5 \\
\hline Chironomidae (N) & 0 & 4 & 4 \\
\hline Culicidae (N) & 0 & 1 & 1 \\
\hline Simulidae (N) & 0 & 1 & 1 \\
\hline Tipulidae (N) & 1 & 1 & 2 \\
\hline Limnobiidae (N) & 0 & 1 & 1 \\
\hline Others NI & 6 & 101 & 107 \\
\hline LEPIDOPTERA & $2(0.5)$ & $90(6.6)$ & $92(5.2)$ \\
\hline DICTYOPTERA & $2(0.5)$ & $27(2)$ & $29(1.6)$ \\
\hline Blattidae & 2 & 26 & 28 \\
\hline Mantidae & 0 & 1 & 1 \\
\hline ISOPTERA & $4(0.9)$ & $4(0.3)$ & $8(0.5)$ \\
\hline Calotermidae & 3 & 3 & 6 \\
\hline Termidae & 1 & 1 & 2 \\
\hline ORTHOPTERA & $4(0.9)$ & $3(0.2)$ & $7(0.4)$ \\
\hline Gryllidae & 4 & 0 & 4 \\
\hline Acrididae & 0 & 1 & 1 \\
\hline Tettigoniidae & 0 & 1 & 1 \\
\hline Others NI & 0 & 1 & 1 \\
\hline Cecidomyiidae (N) & 0 & 7 & 7 \\
\hline Ceratopogonidae $(\mathrm{N})$ & 0 & 5 & 5 \\
\hline Chironomidae (N) & 0 & 4 & 4 \\
\hline Culicidae (N) & 0 & 1 & 1 \\
\hline Simulidae (N) & 0 & 1 & 1 \\
\hline Tipulidae (N) & 1 & 1 & 2 \\
\hline Limnobiidae (N) & 0 & 1 & 1 \\
\hline Others NI & 6 & 101 & 107 \\
\hline LEPIDOPTERA & $2(0.5)$ & $90(6.6)$ & $92(5.2)$ \\
\hline DICTYOPTERA & $2(0.5)$ & $27(2)$ & $29(1.6)$ \\
\hline Blattidae & 2 & 26 & 28 \\
\hline Mantidae & 0 & 1 & 1 \\
\hline ISOPTERA & $4(0.9)$ & $4(0.3)$ & $8(0.5)$ \\
\hline Calotermidae & 3 & 3 & 6 \\
\hline Termidae & 1 & 1 & 2 \\
\hline ORTHOPTERA & $4(0.9)$ & $3(0.2)$ & $7(0.4)$ \\
\hline Gryllidae & 4 & 0 & 4 \\
\hline Acrididae & 0 & 1 & 1 \\
\hline Tettigoniidae & 0 & 1 & 1 \\
\hline Others NI & 0 & 1 & 1 \\
\hline THYSANOPTERA & 0 & $6(0.4)$ & $6(0.3)$ \\
\hline HEMIPTERA & 0 & $2(0.1)$ & $2(0.1)$ \\
\hline NEUROPTERA & 0 & $1(0.1)$ & $1(0.1)$ \\
\hline ARANEAE & $17(4)$ & $16(1.2)$ & $33(1.9)$ \\
\hline Thomisidae & 12 & 12 & 24 \\
\hline Salticidae & 1 & 4 & 5 \\
\hline
\end{tabular}

\begin{tabular}{llll} 
Others NI & 4 & 0 & 4 \\
PSEUDOSCORPIONES & $1(0.2)$ & 0 & $1(0.1)$ \\
OTHER & $1(0.2)$ & 0 & $1(0.1)$ \\
TOTAL & 422 & 1354 & 1776 \\
\hline
\end{tabular}

Appendix 2. Composition of ant species that were trapped in pitchers of $N$. rafflesiana compared for lower and upper pitchers. * refers to ants that were seen visiting the pitchers.

\begin{tabular}{|c|c|c|c|c|}
\hline \multirow[b]{2}{*}{ Type of pitcher } & \multicolumn{2}{|c|}{$\begin{array}{l}\text { Cumulative number } \\
\text { of ants }\end{array}$} & \multicolumn{2}{|c|}{$\begin{array}{l}\% \text { pitchers where } \\
\text { present }\end{array}$} \\
\hline & $\begin{array}{l}\text { Lower } \\
(n=17)\end{array}$ & $\begin{array}{l}\text { Upper } \\
(n=17)\end{array}$ & $\begin{array}{l}\text { Lower } \\
(n=17)\end{array}$ & $\begin{array}{l}\text { Upper } \\
(n=17)\end{array}$ \\
\hline Formicidae & 377 & 553 & 100 & 94.1 \\
\hline \multicolumn{5}{|l|}{ Formicinae } \\
\hline Camponotus sp.1 & 83 & 220 & 76.5 & 70.6 \\
\hline Camponotus sp. $2 *$ & 4 & 0 & 11.8 & 0.0 \\
\hline Camponotus sp. 3 & 1 & 0 & 11.8 & 0.0 \\
\hline Camponotus sp.4 & 0 & 5 & 0.0 & 11.8 \\
\hline Camponotus gigas* & 22 & 19 & 41.2 & 29.4 \\
\hline Polyrhachis sp.1* & 6 & 6 & 23.5 & 23.5 \\
\hline Polyrhachis sp.2 & 1 & 6 & 5.9 & 29.4 \\
\hline Prenolepis sp.1 & 1 & 17 & 5.9 & 23.5 \\
\hline Paratrechina sp.1 & 0 & 7 & 0.0 & 5.9 \\
\hline Anoplolepis gracilipes* & 63 & 6 & 29.4 & 11.8 \\
\hline Oecophylla smaragdina* & 5 & 4 & 11.8 & 5.9 \\
\hline \multicolumn{5}{|l|}{ Myrmicinae } \\
\hline Crematogaster sp. $1^{*}$ & 16 & 52 & 29.4 & 41.2 \\
\hline Crematogaster sp.2* & 21 & 98 & 11.8 & 23.5 \\
\hline Crematogaster sp. $3 *$ & 30 & 21 & 17.6 & 11.8 \\
\hline Monomorium sp. 1* $^{*}$ & 1 & 8 & 5.9 & 11.8 \\
\hline Strumigenys sp. 1 & 3 & 0 & 5.9 & 0.0 \\
\hline Oligomyrmex sp.1 & 25 & 8 & 5.9 & 5.9 \\
\hline Leptothorax sp.1 & 4 & 0 & 5.9 & 0.0 \\
\hline Pheidole sp.1 & 51 & 0 & 23.5 & 0.0 \\
\hline \multicolumn{5}{|l|}{ Pseudomyrmicinae } \\
\hline Tetraponera sp.1 & 0 & 8 & 0.0 & 23.5 \\
\hline \multicolumn{5}{|l|}{ Dolichoderinae } \\
\hline Tapinoma sp. $1 *$ & 0 & 11 & 0.0 & 11.8 \\
\hline Tapinoma sp.2 & 6 & 0 & 5.9 & 0.0 \\
\hline Iridomyrmex sp.1 & 0 & 1 & 0.0 & 5.9 \\
\hline Not identified & 34 & 56 & 58.8 & 17.6 \\
\hline
\end{tabular}

\section{References}

Adam J H 1997 Prey spectra of Bornean Nepenthes species (Nepenthaceae) in relation to their habitat; Pertanika J. Trop. Agric. Sci. 20 121-134 
Beaver R A 1983 The communities living in Nepenthes pitcher plants: fauna and food webs; in Phytotelmata: terrestrial plants as hosts for aquatic insect communities (eds) J H Frank and L P Lounibos (Medford, New Jersey, USA: Plexus Publishing, Inc.) pp 129-160

Blüthgen N and Fledler K 2004 Competition for composition: lessons from nectar-feeding ant communities: Community and evolutionary ecology of nectar; Ecology 85 1479-1485

Bohn H F and Fiederle W 2004 Insect aquaplaning: Nepenthes pitcher plants capture prey with the peristome, a fully wettable water-lubricated anisotropic surface; Proc. Natl. Acad. Sci. USA 101 14138-14143

Brühl C A, Gunsalam G and Linsenmair K E 1998 Stratification of ants (Hymenoptera, Formicidae) in a primary rain forest in Sabah, Borneo; J. Trop. Ecol. 14 285-297

Cheek M and Jebb M 2001 Nepenthaceae; in Flora Malaysiana, S1, Seed Plants (Leiden, the Netherlands: Publication Department of the National Herbarium Nederland) p. 164

Clarke C 1997 Nepenthes of Borneo (Kota Kinabalu, Sabah, Malaysia: Natural History Publications [Borneo])

Clarke C 2001 Nepenthes of Sumatra and Peninsular Malaysia (Kota Kinabalu, Sabah, Malaysia: Natural History Publications [Borneo])

Davidson D W, Cook S C, Snelling R R and Chua T H 2003 Explaining the abundance of ants in lowland tropical rainforest canopies; Science 300 969-972

Di Giusto B, Anstett M-C, Dounias E and McKey D B 2001 Variation in the effectiveness of biotic defense: the case of an opportunistic ant-plant protection mutualism; Oecologia 129 367-375

Di Giusto B, Guéroult M, Rowe N and Gaume L 2008 The waxy surface in Nepenthes pitcher plants: variability, adaptive significance and developmental evolution; in Functional surfaces in biology (ed) S. Gorb (Berlin: Springer) (in press)

Ellison A M, Gotelli N J, Brewer J S, Cochran-Stafira D L, Kneitel J M, Miller T E, Worley A C and Zamora R 2003 The evolutionary ecology of carnivorous plants; Adv. Ecol. Res. 33 $1-74$

Gaume L, Gorb S and Rowe N 2002 Function of epidermal surfaces in the trapping efficiency of Nepenthes alata pitchers; New Phytol. 156 479-489

Gaume L, Perret P, Gorb E, Gorb S, Labat J-J and Rowe N 2004 How do plant waxes cause flies to slide? Experimental tests of wax-based trapping mechanisms in three pitfall carnivorous plants; Arthropod Struct. Dev. 33 103-111

Gaume L, Zacharias M, Grosbois V and Borges R M 2005 The fitness consequences of bearing domatia and having the right ant partner: experiments with protective and nonprotective ants in a semi-myrmecophyte; Oecologia 145 $76-86$

Glossner F 1992 Ultraviolet patterns in the traps and flowers of some carnivorous plants; Bot. Jahrb. Syst. 113 577-587

Gorb E, Haas K, Henrich A, Enders S, Barbakadze N and Gorb S 2005 Composite structure of the crystalline epicuticular wax layer of the slippery zone in the pitchers of the carnivorous plant Nepenthes alata and its effect on insect attachment; J. Exp. Biol. 208 4651-4662
Jaffe K, Blum M S, Fales H M, Mason R T and Cabrera A 1995 On insect attractants from pitcher plants of the genus Heliamphora (Sarraceniaceae); J. Chem. Ecol. 21 379-384

Joel D M 1988 Mimicry and mutualism in carnivorous pitcher plants (Sarraceniaceae, Nepenthaceae, Cephalotaceae, Bromeliaceae); Biol. J. Linn. Soc. 35 185-197

Joel D M, Juniper B E and Dafni A 1985 Ultraviolet patterns in the traps of carnivorous plants; New Phytologist 101 585-593

Juniper B E and Burras J 1962 How pitcher plants trap insects; New Sci. 13 75-77

Juniper B E, Robins R J and Joel D 1989 The carnivorous plants (London, UK: Academic Press)

Kato M, Hotta M, Tamin R and Itino T 1993 Inter- and intra-specific variation in prey assemblages and inhabitant communities in Nepenthes pitchers in Sumatra; Trop. Zool. 6 11-25

Lloyd F E 1942 The carnivorous plants (Waltham, Mass., US: Chronica Botanica Co.)

Lüttge U 1983 Ecophysiology of carnivorous plants; in Encyclopedia of plant physiology (eds) O L Lange, P S Nobel, C B Osmond and H Ziegler (Berlin: Springer) pp 489-517

Massey B S 2006 Mechanics of fluids 8th edition, revised by J A Ward-Smith (ed) (London, New York: Taylor and Francis Routledge)

McKey D B, Gaume L, Brouat C, Di Giusto B, Pascal L, Debout G, Dalecky A and Heil M 2005 The trophic structure of tropical ant-plant-herbivore interactions: community consequences and coevolutionary dynamics; in Biotic interactions in the tropics (eds) D Burslem, M Pinard and S Hartley (Cambridge: Cambridge University Press) pp 386-413

Merbach M A, Zizka G, Fiala B, Maschwitz U and Booth W A 2001 Patterns of nectar secretion in five Nepenthes species from Brunei Darussalam, Northwest Borneo, and implications for ant-plant relationships; Flora 196 153-160

Miles D H, Kokpol U and Mody N V 1975 Volatiles in Sarracenia flava; Phytochemistry 14 845-846

Moran J A 1996 Pitcher dimorphism, prey composition and the mechanism of prey attraction in the pitcher plant Nepenthes rafflesiana in Borneo; J. Ecol. 84 515-525

Moran J A, Booth W E and Charles J K 1999 Aspects of pitcher morphology and spectral characteristics of six Bornean Nepenthes pitcher plant species: implications for prey capture; Ann. Bot. 83 521-528

Moran J A, Merbach M A, Livingston N J, Clarke C M and Booth W E 2001 Termite prey specialization in the pitcher plant Nepenthes albomarginata - evidence from stable isotope analysis; Ann. Bot. 88 307-311

Osunkoya O O, Daud S D, Di Giusto B, Wimmer F L and Holige T M 2007 Construction costs and physio-chemical properties of the assimilatory organs of Nepenthes species in northern Borneo; Ann. Bot. 99 895-906

Newell S J and Nastase A J 1998 Efficiency of insect capture by Sarracenia purpurea (Sarraceniaceae), the northern pitcher plant; Am. J. Bot. 85 88-91

Phillipps A and Lamb A 1996 Pitcher plants of Borneo (Kota Kinabalu, Sabah, Malaysia: Natural History Publications [Borneo]) 
Salmon B 1993 Some observations on the trapping mechanisms of Nepenthes inermis and N. rhombicaulis; Carnivorous Plant Newsletter 23 101-114

Schultze W, Schultze E D, Pate J S and Gillison A N 1997 The nitrogen supply from soils and insects during growth of the pitcher plants Nepenthes mirabilis, Cephalotus follicularis and Darlingtonia californica; Oecologia 112 464-471

Stork N E 2003 Biodiversity; in Encyclopedia of insects (eds) V H Resh and R T Cardé (Academic Press: San Diego, USA)

MS received 05 June 2007; accepted 4 December 2007

ePublication: 25 January 2008

Corresponding editor: RENEE M BoRgES 